\title{
Caucasian clover performance in a year of severe drought
}

\author{
R.N. WATSON, F.J. NEVILLE and N.L. BELL \\ AgResearch, Ruakura Agricultural Research Centre, Private Bag 3123, Hamilton
}

\begin{abstract}
In a year of spring-summer drought on a sandy volcanic ash soil, ryegrass/caucasian clover $(\mathrm{RG} /$ $\mathrm{CC}$ ) and RG/white clover (RG/WC) pastures had similar rapid increases in pasture growth rates during September. Growth rates peaked around 25 October (65-70 kg DM/ha/day) for RG/CC and around 14 October (50-60 kg DM/ha/day) for RG/ WC. As drought intensified the declines in pasture growth rates were similar, but delayed by up to 3 weeks for $\mathrm{RG} / \mathrm{CC}$. Both pastures reached minimum summer growth rates of $<10 \mathrm{~kg} \mathrm{DM} / \mathrm{ha} /$ day at the beginning of February (4\% soil moisture). Spring/ autumn application of nematicide increased pasture growth. WC was almost completely lost from RG/ WC pasture and was largely replaced by summer grass. Drought did not affect CC plant survival, but some leaf wilting and brown-off occurred in February. Autumn pasture recovery was similar except that the recovery of $\mathrm{RG} / \mathrm{CC}$ pasture in the absence of nematicide application was delayed and significantly reduced. The absence of clover and replacement by summer grass reduced autumn response to nematicide by RG/WC. On treated RG/ CC plots there was a $96 \%$ reduction in root galling by the root knot nematode (Meloidogyne hapla) and reduced populations of grass grub (Costelytra zealandica) and clover root weevil (Sitona lepidus) in autumn. This led to a $107 \%$ increase in fine root mass/unit mass of CC rhizome material, compared with untreated CC. These pests depend on, or are favoured by, pasture clover, so that higher populations were retained by the presence of clover in $\mathrm{RG} / \mathrm{CC}$ compared with the $\mathrm{RG} / \mathrm{WC}$ pasture. $\mathrm{CC}$ can be considered as a drought-persistent rather than a drought-resistant plant.
\end{abstract}

Keywords: caucasian clover, drought, persistence, pests, production, ryegrass, Trifolium ambiguum, Trifolium repens

\section{Introduction}

Cost effective pasture production in New Zealand depends on pasture legumes, usually white clover
(Trifolium repens) (WC), for nitrogen inputs and for contributions to forage production, forage quality and feed intake by sheep and cattle (Caradus et al. 1996; Harris et al. 1997). WC is vulnerable to surface soil temperatures in summer which are lethal to stolons (Archer \& Robinson 1989; Brock \& Kim 1994), particularly on light soils in the coastal Bay of Plenty (BOP) where root-feeding pests, especially clover nematodes, add to WC losses and delay recovery after drought (Watson et al. 1994).

Caucasian clover (Trifolium ambiguum) (CC) is closely related to white clover but spreads from rhizomes beneath the ground. This affords better protection of its growing points from summer temperature extremes and overgrazing, facilitating better persistence. This should provide better post-drought recovery, and thus a means of managing for the impact of nematodes. Studies confirm the persistence of CC after drought (Spencer et al. 1975; Woodman et al. 1992; Hill et al. 1996). The present study is the first where persistence and performance of $\mathrm{CC}$ have been evaluated in a dairying system or in warm temperate climatic conditions and pasture pest complexes of northern regions of New Zealand.

Grazed plots containing ryegrass (Lolium perenne) (RG) with WC or CC were established in spring 1994 on Paengaroa sandy soil from volcanic ash at Pongakawa in the coastal BOP (Watson et al. 1996). The 1997/98 spring-summer drought was unprecedented in recent years, providing an opportunity to assess how $\mathrm{CC}$ in a ryegrass pasture responded to drought.

\section{Methods}

The establishment in September 1994 and management of pastures sown with WC or CC have been described (Watson et al. 1996; 1997). Pastures of WC cv. Grasslands Kopu and $\mathrm{CC}$ cv. Endura were sown in 0.125 ha plots, with 4 replicates, into a prepared seedbed after maize cropping. Grazing by dairy cows began in February 1995 and RG was undersown over most of the area in July 1995. During the first three years $5 \times 5$ $\mathrm{m}$ mown subplots were imposed and included $\pm \mathrm{RG}$, and nematicide and fungicide treatments. In September 1997 the original subplots were replaced by new $5 \times 5$ $\mathrm{m}$ subplots in $\mathrm{RG} /$ clover pasture only and \pm nematicide 
treatment only. The nematicide treatment consisted of 5 $\mathrm{kg}$ a.i./ ha fenamiphos watered in at $8 \mathrm{1} / \mathrm{m}^{2}$ on 17 September, followed 5 weeks later by retreatment using $5 \mathrm{~kg}$ a.i./ha oxamyl. On 3 March 1998 fenamiphos was reapplied, with $8 \mathrm{l} / \mathrm{m}^{2}$ water applied to treated and nontreated plots.

Pasture production was assessed from mown plots immediately before grazing, generally about monthly, but intervals were longer during summer drought or winter. In the 1996/97 season, production within grazed pasture was also assessed from $10 \mathrm{~m}$ long mowing strips taken as moving transects (Watson et al. 1997) and this was restarted from December 1997. Mowing from the grazed areas was preceded by collection of pasture samples for herbage dissection. Similar samples were collected from the mown sub-plot areas on a seasonal basis. Fertiliser applications were those applied by the farmer based on soil tests, with the exception of the mown plot areas which had an additional treatment of $30 \%$ potassic serpentine superphosphate in June 1998 to compensate for herbage removal.

Soil insect populations were assessed in May. Forty soil cores $(10 \mathrm{~cm}$ diam. $\times 15 \mathrm{~cm}$ depth $)$ were sampled and hand sorted from each grazed plot area and 15 from the mown sub-plots. Nematode samples $(5$ $\times 25 \mathrm{~mm}$ diam. soil cores to 10 $\mathrm{cm}$ depth) were taken from grazed or mown plot areas periodically throughout the trial. Nematodes were extracted from soil using a variant of the Whitehead tray method. All plant parasitic nematodes were counted by genera under a microscope and total soil nematodes were counted using a Doncaster dish. Clover roots sampled from mown plots were surface sterilised and plated on potato dextrose agar to determine the presence of rootrotting fungi.

Rainfall data have been collected by the farm owner for many years and are supplied to the Meteorological Service (site No. 330). On most visits to the site duplicate samples consisting of $5 \times 25 \mathrm{~mm}$ diam. soil cores to $10 \mathrm{~cm}$ depth were taken for soil moisture determination.

\section{Results}

\section{Rainfall and soil moisture}

The sandy ash soils of the coastal BOP are free-draining and have limited moisture-holding capacity. Thus pasture production is sensitive to rainfall deficit. Annual rainfall since 1984 has ranged from 814 to $1700 \mathrm{~mm}$, which is relatively evenly distributed on a mean monthly basis (data not presented). However, rainfall can vary considerably from month to month (Figure 1). Our data indicate that $\sim 70-80 \mathrm{~mm}$ rainfall $/ \mathrm{month}$, (or $\sim 40-50 \mathrm{ml}$ water $/ 250 \mathrm{ml}$ soil) are required to sustain optimum pasture production potential during the main growing season (September-May). When consecutive months of lower rainfall occurred, production was reduced more markedly. Pasture growth rates (using data from grazed $\mathrm{RG} / \mathrm{CC}$ and $\mathrm{RG} / \mathrm{WC}$ pasture) were reduced by low rainfall in October/November 1996 but were restored by good rainfall in December. In 1997 slightly better September/October rain sustained spring production a few weeks later than in 1996, but growth rates were markedly truncated in November and continued declining to rates equivalent to mid-winter by January/ February 1998 as the deficiency in monthly rainfall continued. Soil moisture dropped as low as $4 \% \mathrm{M}_{\mathrm{W}}$ (or $9 \mathrm{ml}$ water $/ 250 \mathrm{ml}$ soil). Pasture growth rates recovered in March, but autumn rain was insufficient to sustain growth through April.
Figure 1 Monthly rainfall and pasture growth rates of grazed ryegrass with white or caucasian clover, from mid 1996 to mid 1998.

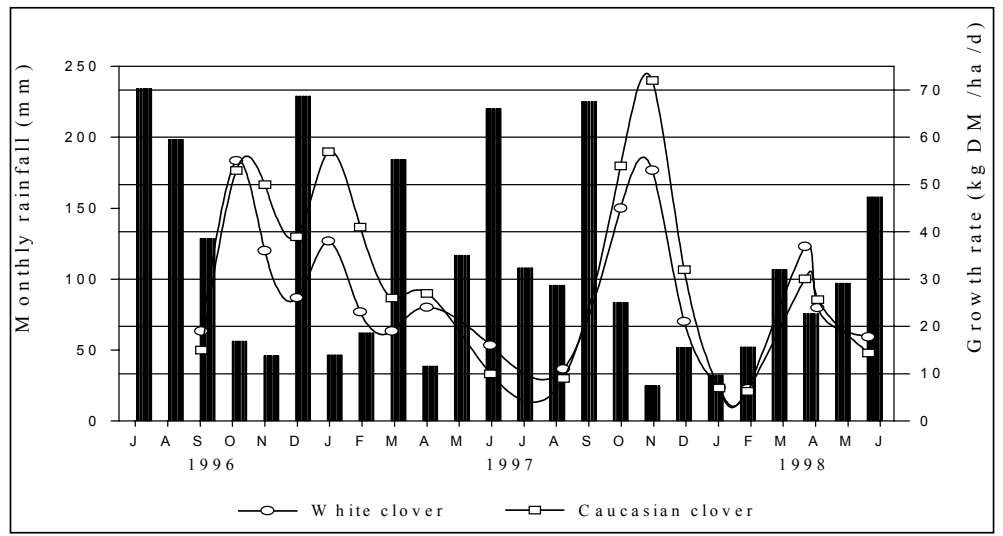

On 11 of the past 14 years $<80 \mathrm{~mm}$ rainfall occurred in at least one month between October and December. November/December rainfall $<160 \mathrm{~mm}$ occurred on 6 occasions. When the lowest November/December rain occurred (1994; $42 \mathrm{~mm}$ ) this was followed by the highest January-March rainfall $(833 \mathrm{~mm})$ in the 14 years. By contrast, the 1997/98 season not only recorded the second lowest November/December rain $(76 \mathrm{~mm})$ but also the lowest January-March $(191 \mathrm{~mm})$ and OctoberMay $(544 \mathrm{~mm})$ rain, making this the driest season in at least 14 years. 


\section{Herbage yield}

Growth curves from the WC and CC pastures followed similar seasonal patterns, with a steep rise from September to a spring peak which was truncated in early November by the onset of drought (Figure 2). RG/ $\mathrm{CC}$ pasture attained a spring growth peak $(65-70 \mathrm{~kg}$ $\mathrm{DM} /$ ha/day) which was higher than for the RG/WC pasture (50-60 $\mathrm{kg} \mathrm{DM} / \mathrm{ha} /$ day) and delayed by about 10 days, suggesting slightly greater tolerance to the onset of drought. The decline in growth rates as the drought intensified was delayed in the RG/CC pasture by up to 3 weeks. January/February growth rates, at the drought apogee declined below $10 \mathrm{~kg} \mathrm{DM} /$ ha/day. There was a pronounced autumn growth flush which peaked in April. This growth peak was again slightly delayed for RG/ CC. Autumn growth peaks for RG/WC plots, and RG/ $\mathrm{CC}$ clover treated with nematicide, were similar (40-50 $\mathrm{kg} \mathrm{DM} / \mathrm{ha} /$ day) but the peak autumn growth rate of untreated $\mathrm{RG} / \mathrm{CC}$ (30 kg DM/ha/day) was markedly reduced.

Figure 2 Pasture growth rates during 1997/98 for mown plots of ryegrass with white or caucasian clover and \pm nematicide treatment. Upper error bars are SED for nematicide response within clover species, lower error bars are SED for clover main effects.

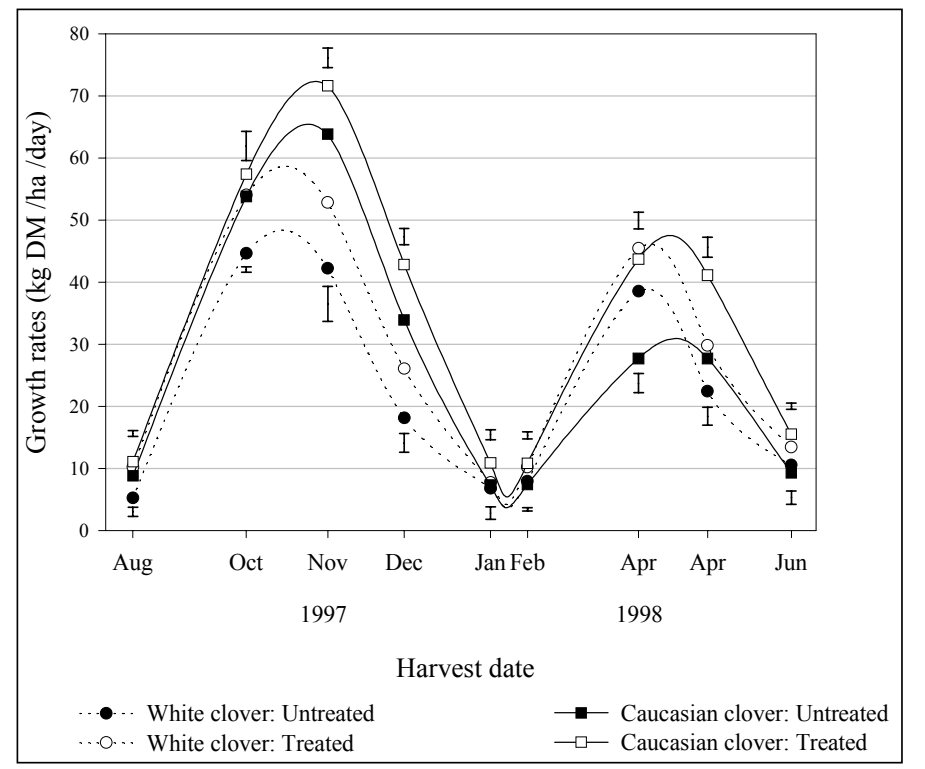

weeds, including a large number of species with either winter or summer activity, made a similar overall contribution in both pastures, but increased slightly in $\mathrm{RG} / \mathrm{WC}$ pasture as it opened up after drought. WC within the RG/WC pasture followed a declining trend from summer 1996/97 and had practically disappeared from pasture by autumn 1998. White clover stolons began to dry up during the onset of drought in both years, producing gaps in the pasture from November/ December largely filled by summer grass. This grass goes to seed during autumn and constituted up to $30 \%$ of autumn DM production on WC/RG plots, but was largely suppressed in RG/CC plots. A small-leaved selfsown local WC ecotype maintained a presence in the $\mathrm{RG} / \mathrm{CC}$ pasture and contributed to pasture legume content most significantly in winter and early spring. The marked contribution to total pasture legume content by $\mathrm{CC}$ is clearly demonstrated, with its major contribution from spring to autumn. A declining trend in CC contribution to pasture was also evident between the 1997 and 1998 summers. Since CC maintained a large biomass of rhizomatous material after the drought, this apparent decline was related to drought-affected plant production rather than plant survival, as in WC. CC remained green until February when some leaves started to brown off and the pasture started to take on a more open appearance. Small plots of lucerne (Medicago sativa cv. Otaio), and volunteer plants of chicory (Cichorium intybus), present and grazed in common with pasture at the trial site, were observed to stay green and maintain active growth through the summer.

\section{Pest effects}

The potential effect of pests and diseases on $\mathrm{CC}$ performance needs to be considered. Both the RG/WC and RG/CC pastures developed and maintained responses to nematicide treatment, with $\mathrm{RG} / \mathrm{CC}$ pasture especially responsive in autumn (Figure 2). Populations of insect pests which are favoured by, or depend on, pasture clover, e.g., grass grub and

\section{Species composition}

$\mathrm{RG}$ made a major contribution to yields in both pastures (Figure 3). Its presence in RG/WC pasture was reduced in summer/autumn, largely owing to the presence of summer grass, and from spring to autumn in $\mathrm{RG} / \mathrm{CC}$ pasture owing to the contribution from CC. Broadleaf clover root weevil respectively, declined along with the loss of clover from RG/WC plots, but were retained at higher levels in RG/CC (Table 1). Populations of Tasmanian grass grub (Aphodius tasmaniae), which is not dependent on clover, were not affected. Nematicide treatment reduced numbers of grass grub and Tasmanian grass grub by $>90 \%$ and clover root weevil by $31 \%$. 
Figure 3 Pasture composition by species and growth rate from January 1997 to June 1998 for ryegrass pastures with (a) white clover and (b) caucasian clover.

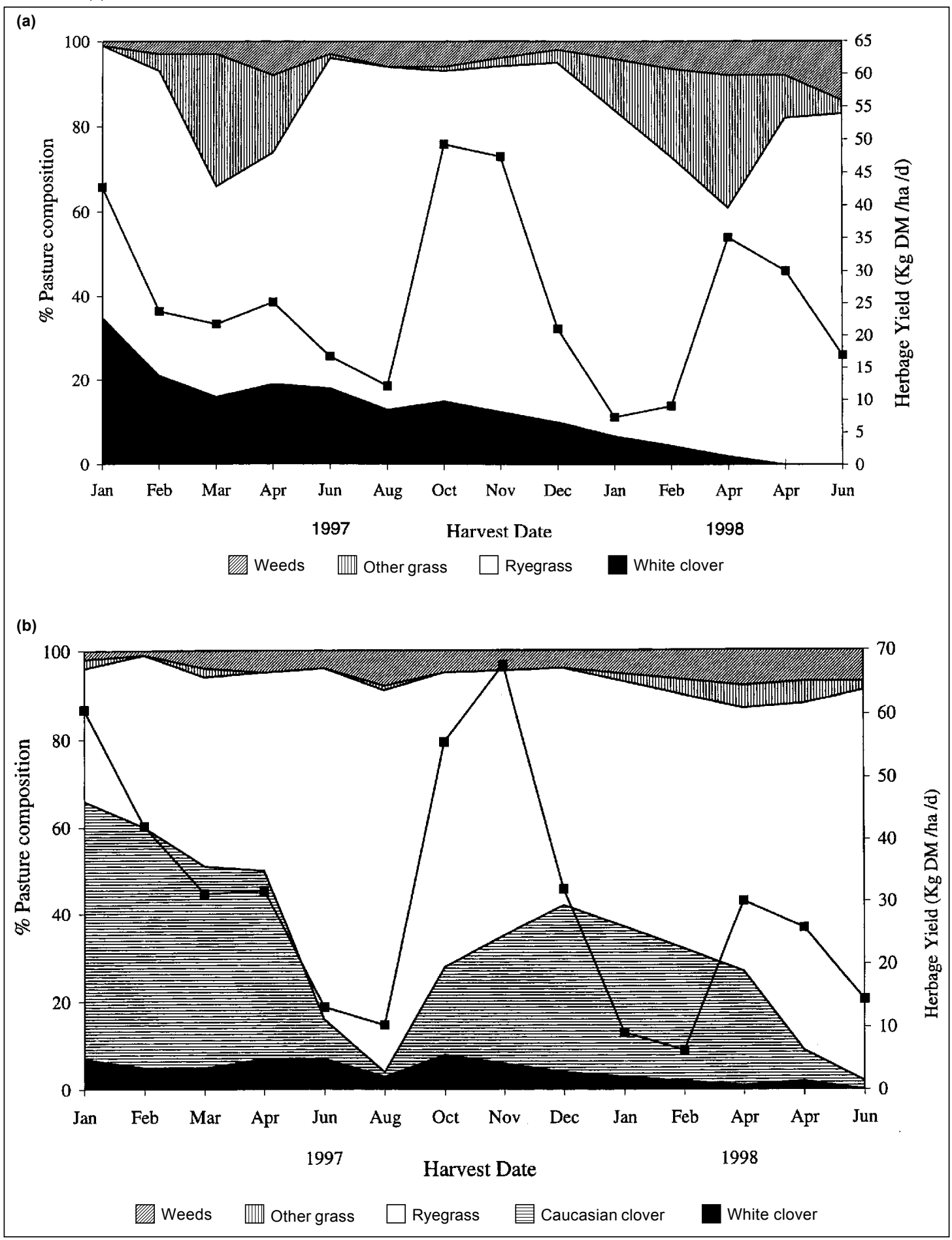


Table 1 Populations in May 1998 of grass grub, Tasmanian grass grub and clover root weevil (no. $/ \mathrm{m}^{2}$ ) in untreated mown and grazed plots of ryegrass pasture with caucasian clover (CC) or white clover (WC) ( \pm SE).

\begin{tabular}{|c|c|c|c|c|c|c|}
\hline & \multicolumn{2}{|c|}{ Grass grub } & \multicolumn{2}{|c|}{$\begin{array}{l}\text { Tasmanian grass } \\
\text { grub }\end{array}$} & \multicolumn{2}{|c|}{$\begin{array}{c}\text { Clover root } \\
\text { weevil }\end{array}$} \\
\hline & Mown & Grazed & Mown & Grazed & Mown & Grazed \\
\hline CC & $176 \pm 13$ & $61 \pm 9$ & $57 \pm 11$ & $37 \pm 8$ & $26 \pm 10$ & $11 \pm 4$ \\
\hline WC & $59 \pm 11$ & $21 \pm 3$ & $93 \pm 22$ & $38 \pm 8$ & 0.3 & 1.0 \\
\hline
\end{tabular}

Root knot nematode (Meloidogyne hapla) was observed to cause heavy damage to fine feeder roots on CC during 1997/98 (Table 2). Root galling by the nematode in May was reduced $96 \%$ as a result of nematicide treatment. This was associated with large increases in nodulation and the number and mass of fine roots on rhizomes, and in leaf size on the CC. effects on summer production, forage quality and nitrogen-fixation, which may carry through to successive seasons.

The accumulated advantages from CC during summer and autumn were greater under a more favourable growing season than in drought (Figure 1). High rainfall in December 1996 maintained better summer pasture growth than in the drier $1997 / 98$ season, and $\mathrm{CC}$ was able to make a greater contribution to production. This implies that CC may have even greater potential in more traditional dairying areas such as the Waikato. Better soil moisture conditions are generally less compromising to $\mathrm{WC}$ persistence than drier dairying areas but this may also allow $\mathrm{CC}$ to better express its superior summer growth potential. Even in the most favourable environments pasture legume content is seldom adequate to support optimum milk production (Harris 1997).

In previous years $\mathrm{RG} / \mathrm{WC}$ pasture was more responsive to nematicide treatment than $\mathrm{RG} / \mathrm{CC}$ pasture, the response increasing from spring through to autumn, and from the second to the third years of the pasture (Watson et al. 1996; 1997). Clover is the most responsive pasture component to nematicide treatment so that the
Root diseases monitored in the clovers showed a similar species diversity and incidence on each clover and were not linked quantitatively to responses on the nematicide treatments (data not presented).

\section{Discussion}

The contribution to summer/autumn production and pasture quality gives $\mathrm{CC}$ good potential for improving animal production in pastoral farming (Taylor \& Watson 1998; Watson et al. 1997). In a year of drought RG/CC pasture had a slightly delayed response to onset of drought compared with a RG/WC pasture, but pasture growth was similar under severe drought. CC has maintained its earlier promise in terms of its contribution to seasonal pasture legume content and persistence. The poor post-drought recovery by CC was unexpected, given the good survival of plant populations and rhizome material. The slow recovery in autumn 1998 may have been be owing to continuing dry conditions through the early autumn to April, as CC normally has markedly declining growth rates by May (Watson et al. 1997). Dry conditions in late spring or early summer can result in pasture opening up and exposing WC stolons to lethal surface temperatures (Watson et al. 1994). The resulting loss of WC then has deleterious lesser response in the RG/WC in 1997/98 is explained by the lack of clover, and replacement by summer grass, which bolted to seed during autumn, providing pasture of reduced quality (Taylor \& Watson 1998). An increased response from the RG/CC may have been influenced by drought not enabling $\mathrm{CC}$ to compensate for the activities of root-feeding pests by production of fresh root growth. In the third year insect pest populations were similar in both pastures (Watson et al. 1997), but in the fourth year, populations of pests that are directly influenced by pasture clover were maintained by $\mathrm{RG} / \mathrm{CC}$, and declined along with the legume in RG/WC plots. This may have implications for the ultimate viability of $\mathrm{CC}$ in northern regions, which will become clearer over the next few years. Clover root weevil became established at the BOP site only in 1995/96 and its population increase would have been limited by the drought in 1997/98 (Addison et al. 1998).

Root impairment from pest attack probably contributed to a large reduction in the abundance of fine root mass on untreated CC in May. This would have affected its performance during and after drought. Two main species of root knot nematodes attack clover in New Zealand, of which M. hapla affected CC at the BOP site. The response by CC to M. trifoliophila, 
which predominates in most northern regions, has not been quantified. This nematode infects both WC and CC (Mercer \& Miller 1997) and reduced seedling vigour of CC when planted into trays of inverted pasture turf in late spring (Watson, pers. obs.). The clover cyst nematode (Heterodera trifolii), which occurs throughout the country, and is also a major pest of $\mathrm{WC}$, has maintained much lower populations in $\mathrm{RG} / \mathrm{CC}$ than in $\mathrm{RG} / \mathrm{WC}$ in the BOP (Watson et al. 1997). Since clover root knot nematodes are absent from southern parts of the South Island, this may provide particular advantages for the use of CC in this environment. $\mathrm{CC}$ is regarded as a favourable plant for the root lesion nematode (Pratylenchus penetrans) (Thies et al. 1995). This, along with other species of root lesion nematode, also occurs widely throughout New Zealand, and is present at the BOP site. The main species, root knot and clover cyst nematodes, are inactive over winter. We have observed that WC roots which have been heavily damaged by nematodes before the start of winter are largely replaced with new fine white roots by spring, when clover is least responsive to nematicide treatment. Such replacement of fine roots may need to occur in $\mathrm{CC}$ for it to fully recover its vigour potential at the start of a new growing season. To this end the greater biomass of rhizome material, in comparison with WC stolon material, is potentially a much more efficient nutrient storage organ for supporting such root regeneration.

\section{Conclusions}

Under favourable growing conditions, established RG/ $\mathrm{CC}$ pasture has the potential to outyield RG/WC pasture and maintain a higher legume content through the summer/autumn. CC did not increase pasture growth during intense drought, although plant survival was markedly superior to $\mathrm{WC}$, and this helped to suppress invasion of the pasture by summer grass. Thus CC continued to demonstrate a potential to improve animal production by improving pasture legume performance and forage quality. Pasture pests that are advantaged by the presence of clover retained greater populations in $\mathrm{RG} / \mathrm{CC}$ than in RG/WC pasture after drought. The full implications of this for $\mathrm{CC}$ in northern regions have yet to be determined. $\mathrm{CC}$ can be regarded as more a droughtpersistent than a drought-resistant pasture legume.

\section{ACKNOWLEDGEMENTS}

We gratefully acknowledge the assistance from Margaret and Rex Benner, Pongakawa, for their very generous farm hosting; from Catherine Cameron and Gabriella Burch, AgResearch, Ruakura, for their biometrical and microbiological inputs respectively; Wrightson Nutrition, Christchurch, for supporting some of the data collection; and the New Zealand Foundation for Research Science and Technology for financially enabling this research.

\section{REFERENCES}

Addison, P.J.; Willoughby, B.E.; Hardwick, S.; Gerard, P.J. 1998. Clover root weevil: observations on differences between 1997 and 1998 summer populations in the Waikato. Proceedings of the New Zealand Plant Protection Conference 51: 1-4.

Archer, K.A.; Robinson, G.G. 1989. The role of stolons and seedlings in the persistence and production of white clover (Trifolium repens $\mathrm{cv}$. Huia) in temperate pastures on the Northern Tablelands, New South Wales. Australian journal of agricultural research 40: 605-616.

Brock, J.L.; Kim, M.C. 1994. Influence of the stolon/ soil surface interface and plant morphology on the survival of white clover during severe drought stress. Proceedings of the New Zealand Grassland Association 56: 187-191.

Caradus, J.R., Woodfield, D.R.: Stewart, A.V. 1996. Overview and vision for white clover. pp.1-6. In: Woodfield, D.R. (ed.) White clover: New Zealand's Competitive Edge. Agronomy Society of New Zealand Special Publication No. 11/Grassland Research and Practice Series No. 6.

Harris, S.L. 1997. The performance of clover in dairy pastures. Dairy Farming Annual 49: 142-149.

Harris, S.L; Clarke, D.A.; Auldist, M.J.; Waugh, C.D.; Laboyrie, P.G. 1997. Optimum white clover content for dairy pastures. Proceedings of the New Zealand Grassland Association 59: 29-33.

Hill, M.J.; Mulcahy, C.; Rapp, G.G. 1996. Perennial legumes for the high rainfall zone of eastern Australia. 1. Evaluation in single rows and selection of Caucasian clover (Trifolium ambiguum M. Bieb). Australian journal of experimental agriculture 36: 151-163.

Mercer, C.F.; Miller, K.J. 1997. Evaluation of 15 Trifolium spp. and of Medicago sativa as hosts of four Meloidogyne spp. found in New Zealand. Supplement to the journal of nematology 29(4S): 673-676.

Spencer, K.; Govaars, A.G.; Zorin, M.; Hamilton L.J. 1975. Adaptability of Trifolium ambiguum Bieb. to a Victorian montane environment. Journal of the Australian Institute of Agricultural Science 41: 268270.

Thies, J.A.; Petersen, A.D.; Barnes, D.K. 1995. Host suitability of forage grasses and legumes for root- 
lesion nematode, Pratylenchus penetrans. Crop science 35: 1647-1651.

Taylor G.H.; Watson, R.N. 1998. A preliminary costbenefit analysis for inclusion of Caucasian clover in new dairy pasture. Proceedings of the New Zealand Grassland Association 60: 127-133.

Watson, R.N.; Bell, N.L.; Neville, F.J.; Harris, S.L. 1994. Improving pasture sustainability by reducing the impact of clover nematodes. pp. 83-85. In: Pankhurst, C.E. (ed.) Soil Biota: Management in Sustainable Farming Ecosystems. CSIRO, Australia. Watson, R.N.; Neville, F.J.; Bell, N.L.; Harris, S.L. 1996. Caucasian clover as a pasture legume for dryland dairying in coastal Bay of Plenty. Proceedings of the New Zealand Grassland Association 58: 183-188.

Watson, R.N.; Neville, F.J.; Bell, N.L.; Harris, S.L. 1997. Caucasian clover for improving summer production in northern regions of New Zealand. Proceedings of the New Zealand Grassland Association 59: 227-232.

Woodman, R.A.F.; Keoghan, J.M.; Allan, B.E. 1992. Pasture species for drought-prone lower slopes in the South Island high country. Proceedings of the New Zealand Grassland Association 54: 115-120. 